\title{
La potestad sancionadora de las administraciones públicas en el ámbito tributario
}

\author{
Antonio Vaquera García ${ }^{1}$
}

Sumario: I. INTRODUCCIÓN. II. PRINCIPIOS DE LA POTESTAD SANCIONADORA EN EL ÁMBITO TRIBUTARIO. CAUSAS EXIMENTES DE LA RESPONSABILIDAD. III. SUJETOS INTERVINIENTES EN LAS INFRACCIONES Y SANCIONES TRIBUTARIAS. IV. LAS INFRACCIONES TRIBUTARIAS. 1. Concepto. 2. Tipificación en la Ley General Tributaria. V. LAS SANCIONES TRIBUTARIAS. 1. Tipificación. 2. Criterios de graduación y cuantificación. 3. Procedimiento sancionador tributario. 4. Ejecución de las sanciones tributarias. VI. EXTINCIÓN DE LA RESPONSABILIDAD POR INFRACCIONES Y SANCIONES TRIBUTARIAS. 1. Extinción de la responsabilidad por infracciones. Causas eximentes de la responsabilidad (reenvío). 2. Extinción de la responsabilidad por sanciones.

\section{INTRODUCCIÓN}

La Administración pública dispone de diferentes potestades para llevar a cabo sus cometidos en aras a la consecución de los principales funciones que tiene encomendadas. Una de ellas consiste en proteger los bienes jurídicos que se definen como tales en el ordenamiento de nuestro país; para ello, acude a los mecanismos de coerción correspondientes, que, de acuerdo a la teoría penal del delito pueden oscilar entre la pena privativa de libertad y las sanciones económicas. En todo caso, la función de dicha potestad consiste tanto en una prevención general como especial de las conductas infractoras, así como de la reparación del daño causado y del hipotético castigo de dichas actuaciones.

Esta potestad sancionadora es única para toda la Administración, si bien se tiende a dividir entre las diversas manifestaciones y campos de actuación de los poderes públicos, para, de ese modo, operar de manera más eficaz y apropiada para cada tipo de ilícito². Sin embargo, como es bien conocido, no se debe olvidar el mandato del

1 Profesor Titular de Derecho Financiero. Universidad de León.

2 Vid., en este sentido: Merino Jara, I.: “Algunas reflexiones sobre la potestad sancionadora de la Administración tributaria”, Impuestos, tomo II, 1987, pp. 224 y ss. y Lozano Cutanda, B.: “Panorámica gene- 
art. 25-3 de la Constitución, cuando establece que "la Administración civil no podrá imponer sanciones que, directa o subsidiariamente, impliquen privación de libertad"; esto supone que para dichas penas hay que acudir a la jurisdicción penal, lo que nos permite avanzar desde este momento que el objeto de este trabajo no va a versar sobre los llamados delitos contra la Hacienda Pública, pues nos situaríamos en un terreno al margen de la Administración y, por ende, excederíamos los límites de este estudio3.

Es, por lo tanto, en este contexto, donde se enmarca la concreción de dicha potestad en el ámbito tributario, por lo que podemos hablar de una auténtica variante de la misma en la esfera fiscal, tema al que dedicamos el contenido de este trabajo4.

Para llevar a cabo nuestro estudio dividiremos la exposición en cinco bloques: en primer lugar, abordaremos, a modo de preparación e introducción general del tema, los principios que inspiran a la Administración tributaria en este terreno (Capítulo I del Título IV de la Ley 58/2003, de 17 de diciembre, General Tributaria -en adelante LGT-); en segundo término, señalaremos los sujetos que intervienen en las infraccio-

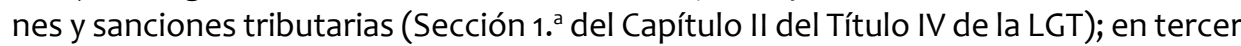
lugar, examinaremos la tipología de las infracciones tributarias vigentes, con la exposición de la evolución que han sufrido desde su primitiva regulación hasta la actuali-

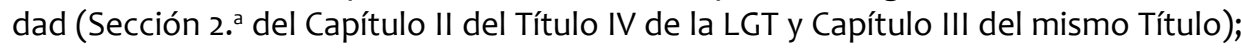
el cuarto bloque se ocupa de las sanciones que corresponden a dichas infracciones (en la misma Sección 2. ${ }^{\text {a }}$ y en la Sección $3 .{ }^{a}$ del Capítulo II del Título IV de la LGT), así como del procedimiento sancionador (Capítulo IV del Título IV de la LGT); en último lugar, abordaremos los modos de extinción de la responsabilidad tanto por infracciones como por sanciones (Sección $4 .{ }^{a}$ del Capítulo II del Título IV de la LGT)5.

ral de la potestad sancionadora de la Administración en Europa: ‘despenalización' y garantía”, Revista de la Administración Pública, núm. 121, 1990, pp. 393 y ss.

3 Ello no impide que la normativa administrativa se inspire en una gran parte de los principios de carácter penal, como comprobaremos oportunamente en el siguiente epígrafe; así, en palabras de Simón Acosta, E.: "las sanciones administrativas tienen la misma naturaleza jurídica que las penas. Derecho penal y Derecho sancionador son dos formas de manifestarse una misma realidad informada por los mismo principios jurídicos". (Vid.: "Capítulo IX. La Potestad Sancionadora”, en la Obra Colectiva: Comentarios a la Ley General Tributaria, 2. ${ }^{a}$ ed., Civitas-Thomson Reuters, Pamplona, 2009, p. 810).

4 En opinión de Simón Acosta, E.: "Desde un punto de vista dogmático la potestad sancionadora no es una potestad típicamente administrativa. En el Estado constitucional, informado por el principio de separación de poderes, la Administración aplica la ley cuando existe algún interés público concreto, pero la aplicación del Derecho cuando no concurre otro interés público que el genérico de defensa y eficacia del propio ordenamiento corresponde a los jueces" (Ibidem, p. 808).

5 Para una visión general de la jurisprudencia emanada de la anterior regulación en la LGT de 1963, véase por todos: Aragonés Beltrán, E.: "Visión jurisprudencial de las infracciones y sanciones tributarias en el ordenamiento jurídico español", Revista Iberoamericana de Derecho Tributario, núm. 3, 1996, pp. 497 y ss.

A su vez, resultan interesantes los siguientes trabajos, principalmente a efectos del Derecho comparado, publicados en la misma Revista Iberoamericana de Derecho Tributario, núm. 4, 1997: Manzini, F.: “Los $170 \begin{aligned} & \text { principios deducibles del ordenamiento comunitario en relación a los sistemas sancionadores de los Esta- } \\ & \text { dos miembros", pp. } 13 \text { y ss.; Burgio, M: “Las sanciones tributarias en la experiencia europea”, pp. } 43 \text { y ss.; }\end{aligned}$ 


\section{PRINCIPIOS DE LA POTESTAD SANCIONADORA EN EL ÁMBITO TRIBUTARIO. CAUSAS EXIMENTES DE LA RESPONSABILIDAD}

Ya hemos adelantado que la potestad sancionadora de la Administración tiene un único modo de actuar, si bien se desarrollan diversas adaptaciones a cada una de las vertientes en las que despliega su actividad; por ello, las máximas que inspiran la actuación del ius puniendi tributario no pueden diferir mucho de las más genéricas del Derecho Administrativo Sancionador ${ }^{6}$. En consecuencia, muchos de los principios que vamos a comentar comparten razón de ser con los propios del Derecho Administrativo -si no son auténticas concreciones al ámbito fiscal de los mismos-e, incluso, del Derecho Penal?.

Como es lógico, todos los fundamentos básicos provienen en última instancia de la Constitución Española de 1978 y, por lo tanto, son de general aplicación tanto a todas las Administraciones públicas, como a la totalidad de los ciudadanos-administrados; sin embargo, como indica la doctrina, ello no obsta a que "cada una de estas administraciones pueda adaptar sus procedimientos materiales a las características que le son propias. Ahora bien, el régimen jurídico debe ser común a todas ellas"8.

Del Federico, L.: "Sanciones indirectas, impropias y atípicas en el ordenamiento tributario italiano”, pp. 201 y ss. y Alarcón García, G. y Beuth, I.: “Los asesores fiscales como sujetos activos de delitos e infracciones tributarias en el ordenamiento alemán”, pp. 229 y ss.

6 Más aún cuando se pone en relación con las garantías y principios del Derecho Penal, como ha puesto de manifiesto el Tribunal Constitucional en su Sentencia 18/1981, de 8 de junio, en la que se puede leer lo siguiente: “(...) los principios inspiradores del orden penal son de aplicación, con ciertos matices, al derecho administrativo sancionador, dado que ambos son manifestaciones del ordenamiento punitivo del Estado, tal y como refleja la propia Constitución, y una muy reiterada jurisprudencia de nuestro Tribunal Supremo (...), hasta el punto de que un mismo bien jurídico puede ser protegido por técnicas administrativas o penales, si bien en el primer caso con el límite que establece el propio artículo 25, en su número 3. ${ }^{\circ}$, al señalar que la Administración Civil no podrá imponer penas que directa o subsidiariamente impliquen privación de libertad". Vid. para un mayor detalle: García de Enterría, E.: “El problema jurídico de las sanciones administrativas”, Revista Española de Derecho Administrativo, núm. 10, 1976, pp. 409 y ss. y Cordero García, J.A.: "La potestad sancionadora de la Administración Tributaria: principios reguladores", Jurisprudencia Tributaria, núm. 5, 2000, pp. 20 y ss.

7 Como advierte Martín Retortillo, L.: “... el estudio de las sanciones administrativas ha de hacerse siempre buscando siempre el contraste con la legislación penal. Ningún sentido tiene estudiar aquella figura en solitario. Cualquier intento de solución y, por supuesto, su ponderación y estudio, no puede llevarse a cabo sin tener en cuenta las fórmulas penales... Cada vez el Tribunal Constitucional está usando con más frecuencia la fórmula 'poder punitivo del Estado' para aludir, conjuntamente, a lo sancionatorio penal y a lo sancionatorio administrativo: son sectores que no pueden andar por separado por más que ofrezcan diferencias". (Vid.: "Las sanciones administrativas en relación con la defensa de los consumidores, con especial referencia a la publicidad de las mismas”, Revista de la Administración Pública, núm. 126, 1991, p. 134). Por su parte, Pont Mestres, M. considera, con acierto a nuestro parecer que "dentro del ordenamiento punitivo se alojan las dos manifestaciones del mismo, cuales son las ceñidas al orden penal y la correspondiente al Derecho Administrativo Sancionador, dentro del que se ubica el Derecho Tributario en lo que concierne a infracciones". (Vid.: "Hacia la superación de una ceremonia de confusión: delimitación del concepto de infracción en el Derecho Tributario vigente", Revista de Derecho Financiero y de Hacienda Pública, núm. 197, 1988, p. 973).

8 Vid.: Hernanz Martín, A.: “Las sanciones en la Ley General Tributaria y en el Reglamento Sancionador”, Información Fiscal, núm. 66, 2004, p. 57. 
Por lo tanto, comprobaremos inmediatamente que existe una sola categoría de principios aplicables a todas las manifestaciones del poder punitivo del Estado, con las matizaciones correspondientes o las adaptaciones que sean precisas, debido a las particularidades de las sanciones administrativas y, más concretamente, las tributarias.

Para ello, la Ley General Tributaria, en su art. 178, fija los principios de la potestad sancionadora en la materia fiscal con el siguiente tenor literal:

"La potestad sancionadora en materia tributaria se ejercerá de acuerdo con los principios reguladores de la misma en materia administrativa con las especialidades establecidas en esta ley.

En particular serán aplicables los principios de legalidad, tipicidad, responsabilidad, proporcionalidad y no concurrencia. El principio de irretroactividad ser aplicará con carácter general, teniendo en consideración lo dispuesto en el apartado 2 del artículo 10 de esta ley"'.

A dicha mención legal hay que añadir lo que dispone el apartado 1 de la Disposición Adicional Quinta de la Ley 30/1992, de 26 de noviembre, de Régimen Jurídico de las Administraciones Públicas y del Procedimiento Administrativo Común, cuando prevé que: "Ios procedimientos tributarios y la aplicación de los tributos se regirán por la Ley General Tributaria, por la normativa sobre derechos y garantías de los contribuyentes, por las Leyes propias de los tributos y las demás normas dictadas en su desarroIlo y aplicación. En defecto de norma tributaria aplicable, regirán supletoriamente las disposiciones de la presente Ley".

De la atenta lectura de los preceptos transcritos se deduce claramente que, si bien el Derecho Administrativo es, con carácter general, supletorio del Derecho Tributario, no sucede así con las infracciones y sanciones fiscales, pues éstas quedan al margen de la citada Disposición Adicional, lo que permite concluir, con la argumentación literal de la propia dicción del art. 178 de la LGT, que los principios administrativos son directamente aplicables a la materia tributaria; en efecto, más aún cuando se observa que la LGT se limita a desarrollar únicamente las máximas de la responsabilidad y la no concurrencia en los dos artículos siguientes ${ }^{10}$ (179 y 180 de la LGT) y la

Este autor resume de una manera muy interesante y sencilla la aplicación de ese ius puniendi de la Administración tributaria, cuando escribe: “Para que la Administración tributaria pueda imponer un castigo al presunto responsable debe dar, previamente, una serie de pasos. En primer lugar, debe analizar objetivamente la acción u omisión del sujeto, para cerciorarse de que la misma encaja en el supuesto típico y antijurídico recogido en la norma... además, que el órgano administrativo pruebe que el sujeto actuó culpablemente... A través de la sanción se pretende refrenar la conducta antijurídica del sujeto, para ello los poderes públicos pueden establecer medidas disuasorias y ejemplarizantes que no son sino verdaderas limitaciones de derechos subjetivos..." (Ibidem, pp. 55 y 56 ).

9 Dicho apartado 2 del art. 10 de la LGT establece: "Salvo que se disponga lo contrario, las normas tributarias no tendrán efecto retroactivo y se aplicarán a los tributos sin período impositivo devengados a partir de su entrada en vigor y a los demás tributos cuyo período impositivo se inicie desde ese momento". Volveremos en el texto sobre el tema de la irretroactividad al aplicarla sobre las infracciones tributarias.

10 Hermosín, M., entiende que al margen de los principios enumerados en el art. 178 de la LGT,

172 también se pueden aplicar al "Ordenamiento sancionador tributario los siguientes: Garantía de procedi- 
irretroactividad en el art. 10-2, con lo que, para el resto, se remite de manera implícita a la norma administrativa. A continuación nos ocupamos de todos ellos, haciendo especial hincapié en los contenidos en la LGT.

El primer principio es el de legalidad, por el que se exige que sea una norma con rango legal la que establezca las infracciones y sus correspondientes sanciones, aunque nada impide que las leyes se remitan a los reglamentos para cuestiones de detaIle, siempre que quede sobradamente cubierto dicho principio; en este ámbito, podemos citar el Reglamento General del Régimen Sancionador Tributario, aprobado por Real Decreto 2063/2004, de 15 de octubre (en adelante RGRST), que se ocupa de concretar aspectos esenciales como el detalle de algunas infracciones y sanciones y del procedimiento sancionador tributario, a las que haremos las oportunas referencias a lo largo de este estudio ${ }^{11}$.

A continuación el precepto de la LGT menciona la tipicidad, entendiéndose como la necesaria mención en la norma con rango legal de todos los elementos esenciales de la conducta infractora, de forma que se obtenga la seguridad jurídica necesaria para que se conozca sobradamente que dicha actuación puede dar lugar a un ilícito tributario $^{12}$. Ahorramos todo ulterior comentario a esta máxima, pues no es sino la transposición a este terreno de la extensamente definida en el campo penal.

El principio de responsabilidad sí que se encuentra desarrollado en la LGT, ya que su art. 179 se refiere a supuestos de no responsabilidad en el apartado 2, cuando establece:

"Las infracciones u omisiones tipificadas en las leyes no darán lugar a responsabilidad por infracción tributaria en los siguientes supuestos:

miento (artículo 134.3 Ley 30/1992); Derecho a ser informado de la acusación, de la identidad de las autoridades instructora y decisoria, derecho a formular alegaciones y a utilizar los medios de prueba pertinentes (artículo 135 Ley 30/1992); Derechos de los ciudadanos contemplados en la Ley 30/1992: conocer el estado de la tramitación, acceso a los registros, derecho a obtener copias, etc.; Principios procesales incardinados en el derecho a la tutela judicial efectiva (artículo 24 de la Constitución): a) acceso al recurso ante la autoridad judicial, b) necesidad de la existencia de un procedimiento con todas las garantías: información sobre la infracción imputada, actividad probatoria, audiencia de los interesados, derecho a no declarar ni a autoincriminarse y derecho a una resolución motivada, c) presunción de inocencia, d) prueba de culpabilidad, e) procedimiento sin dilaciones indebidas". (Vid.: Procedimiento Sancionador Tributario. Cuestiones Problemáticas, Thomson-Aranzadi, Pamplona, 2008, p. 36).

11 Como escribe Hernanz Martín, A.: "El principio de legalidad 'nullum crimen, nulla poena sine previa lege' consagrado en el artículo 25 de la Constitución exige, según reiterada doctrina del Tribunal Constitucional, una doble garantía. Por un lado, material, que requiere la existencia de la una ley (lex scripta) que sea anterior al hecho sancionado (lex previa) y que describa un supuesto estrictamente determinado (lex certa). Y, por otro lado, formal, imponiendo que la norma tipificadora de la infracción y reguladora de la sanción constituya por su rango un precepto de ley”. (Vid.: "Las sanciones en la Ley General Tributaria y en el Reglamento sancionador", ob. cit., p. 57).

12 En palabras del Tribunal Constitucional en su Sentencia de 11 de marzo de 1996: "se exige también la tipicidad o descripción estereotipada de las acciones o de las omisiones indiscriminadas, con indicación de las simétricas penas o sanciones". Tanto es así, que no es posible aplicar por analogía las normas definidoras de infracciones y sanciones, como sostiene Hernanz Martín, A.: Ibidem, p. 58. 

tributario.

a) Cuando se realicen por quienes carezcan de capacidad de obrar en el orden

b) Cuando concurra fuerza mayor.

c) Cuando deriven de una decisión colectiva, para quienes hubieran salvado su voto o no hubieran asistido a la reunión en que se adoptó la misma.

d) Cuando se haya puesto la diligencia necesaria en el cumplimiento de las obligaciones tributarias (...).

e) Cuando sean imputables a una deficiencia técnica de los programas informáticos de asistencia facilitados por la Administración tributaria para el cumplimiento de las obligaciones tributarias".

Todas estas circunstancias contenidas en el precepto transcrito son auténticas causas eximentes de la responsabilidad por infracciones tributarias, es decir, son supuestos en los que no existe culpabilidad del sujeto. Su finalidad originaria consiste en evitar los efectos negativos derivados de una concepción objetiva del ilícito tributario, sin bien, suponen la mayoría de ellas reiteración de eventos ya contenidos en otras disposiciones generales, por lo que se podría considerar que son una enumeración, en cierto modo, superflua ${ }^{13}$.

También se puede plantear el interrogante acerca de su consideración como circunstancias ejemplificativas o con carácter cerrado, es decir, como numerus clausus. La respuesta a esta pregunta permite las dos interpretaciones, tanto a favor como en contra de la consideración como lista cerrada; en efecto, por una parte se puede pensar que la norma no puede contener la totalidad de los supuestos, máxime cuando se contienen otros en distintos preceptos de la LGT, como la regularización (art. 179-3 LGT) y la reducción de sanciones (art. 188 LGT) que también excluyen la responsabilidad. A su vez, y ya no como causas eximentes, sino como causas de extinción de la responsabilidad se encuentran las mencionadas en el art. 189 y 190 LGT $^{14}$; pero en contra, se puede alegar que en el art. 178 de la LGT no se contiene la expresión "entre otros", que ha dado lugar tradicionalmente a entender que tal tipo de ejemplificación es de numerus apertus. A nuestro parecer, consideramos más adecuada la primera interpretación, más acorde con la protección de la seguridad jurídica y con el derecho a la tutela judicial efectiva.

13 Como opina Simón Acosta, E.: "La enumeración de los casos de ausencia de responsabilidad contenida en el artículo 179.2 LGT sigue siendo tributaria de la rigidez de perspectiva de la ley anterior. Los supuestos que en él se enumeran siguen siendo sustancialmente los mismos y en la mayoría de ellos no concurre ni el más mínimo atisbo de responsabilidad. Se trata, por tanto, de menciones superfluas que se aplicarían aun en el caso de que se hubiera guardado silencio sobre ellas". (Vid.: "Capítulo IX. La Potestad Sancionadora", ob. cit., p. 821).

174 epígrafes.

14 De todos ellos nos ocuparemos a lo largo de este trabajo ya sea en éste o en posteriores 
Pasando a abordar cada una de las eximentes del citado art. 179-2 de la LGT, la primera consiste en la ausencia de capacidad de obrar en el ámbito tributario; en este sentido, nos encontramos con una causa de inimputabilidad y no de no culpabilidad, puesto que, evidentemente, el que no tiene capacidad de obrar no tiene siquiera capacidad de ser sujeto infractor y no tiene sentido eximirle de una responsabilidad imposible. Por otro lado, aquellos que no tienen capacidad de obrar actúan en el ámbito tributario, como es sabido, a través de su representante legal (arts. 44 y 45 de la LGT), que será quien asuma la condición de infractor, como ordena el art. 181-1-f) del mismo cuerpo legal.

La segunda causa eximente es la fuerza mayor, mención que también podría haberse obviado en el precepto, ya que no habrá acción típica infractora sin dolo o culpa, a tenor del art. 183-1 de la LGT, cuando define las propias infracciones tributarias, como analizaremos oportunamente.

La tercera causa es salvar el voto o no haber asistido a una reunión en la que se tomó una decisión colectiva. En este caso se exime de responsabilidad a unos sujetos concretos que, por otro lado, no han cometido infracción alguna; en consecuencia, pensamos que no habría ni siquiera tipicidad en dicha conducta y que también podría haberse evitado el citar este supuesto.

A continuación, el citado art. 179-2 de la LGT se refiere a la diligencia necesaria en el cumplimiento de las obligaciones tributarias; para su exposición, la norma trata de explicar lo que se entiende por tal con el siguiente tenor literal: "entre otros supuestos, se entenderá que se ha puesto la diligencia necesaria cuando el obligado haya actuado amparándose en una interpretación razonable de la norma o cuando el obligado tributario haya ajustado su actuación a los criterios manifestados por la Administración tributaria competente en las publicaciones y comunicaciones escritas a que se refieren los artículos 86 y 87 de esta ley. Tampoco se exigirá esta responsabilidad si el obligado tributario ajusta su actuación a los criterios manifestados por la Administración en la contestación a una consulta formulada por otro obligado, siempre que entre sus circunstancias y las mencionadas en la contestación a la consulta exista una igualdad sustancial que permita entender aplicables dichos criterios y éstos no hayan sido modificados". Las comunicaciones e informaciones referidas se publican por parte del Ministerio de Economía y Hacienda y las consultas se remiten a la Dirección General de Tributos, con el efecto vinculante que ha instaurado como novedad la LGT de 2003 (arts. 88 y 89).

El problema está en determinar cuándo debe entenderse que se han llevado a cabo las obligaciones tributarias con la diligencia necesaria. Para los Tribunales, ésta se da cuando el sujeto facilita a la Administración todos los datos, de tal forma que es posible liquidar el tributo. En otras palabras, que no exista ocultación y que no sea necesaria una actuación de investigación de la Inspección de los Tributos ${ }^{15}$.

15 Vid.: Sentencia del Tribunal Supremo de 10 de noviembre de 1999 (RJ, 1999, 9600). En ella se afirma que "existirá infracción tributaria grave (...) cuando el sujeto pasivo deje de ingresar por falta de pre- 
En el mismo sentido, el concepto de interpretación razonable de la norma carece de determinación y habrá que acudir a si existe duda razonable en la misma, si ha surgido jurisprudencia contradictoria de los Tribunales o cuando se trate de una materia con una creciente proliferación normativa y de difícil interpretación.

En cuanto a las publicaciones, comunicaciones y contestaciones a consultas a que se refiere la Ley, no hay problema para las primeras, ya que son las contenidas en los arts. 86 y 87 de la LGT. A su vez, creemos que el precepto no impide que dentro de ellas deban incluirse aquellas publicaciones que bajo el título de "Manuales Prácticos", son las guías para la confección de las autoliquidaciones de algunos tributos y que se publican anualmente ${ }^{16}$; en ellas, la Administración vierte sus opiniones y su parecer interpretativo respecto de la liquidación de cada uno de los gravámenes, al mismo tiempo que se ofrecen ejemplos del parecer y de la técnica que se considera correcta por parte de la Administración tributaria. En cuanto a las segundas -las contestaciones a consultas tributarias-, hay que tener en cuenta que siempre existirá alguna materia respecto a la cual no exista criterio de la Administración Tributaria. Por lo tanto, al contribuyente no se le puede exigir que realice una consulta. En definitiva, una diferencia de criterio no puede conllevar, sin más, el establecimiento de una sanción ${ }^{17}$.

En último lugar, el art. 179-2 menciona las deficiencias técnicas de los programas informáticos ofrecidos por la Administración tributaria para ayudar a la confección de las liquidaciones de algunos tributos. Se trata de una previsión lógica y, por otro lado, a medida que avanzan las nuevas tecnologías y se generalizan los procedimientos telemáticos, necesaria. Lo que hubiese sido inadmisible es que un error informático provocase un incumplimiento sancionable.

Hay que señalar, además, que la conducta no es punible ni aun cuando el error sea detectable y comprensible por un contribuyente con conocimientos elementales de informática; por el contrario, el problema estará en demostrar que dicho error se ha debido a una deficiencia técnica.

Finalmente, para terminar con las eximentes de responsabilidad mencionadas en el citado art. 179-2 de la LGT, hay que advertir de la ausencia de dos causas que pueden tener bastante influencia en el ámbito fiscal. Se trata, en primer lugar, de la supresión de la buena fe, que sí que aparecía en el art. 33 de la Ley 1/1998, de 26 de febrero, de Derechos y Garantías de los Contribuyentes y que fue derogada por la

sentación de la declaración-autoliquidación, sin que la Administración Tributaria conozca la realización del hecho imponible o sus principales elementos y necesite de dicha declaración para conocerlos y para el ingreso de la obligación tributaria correspondiente, por lo que si no se presentan, sólo puede conocer estos hechos y cobrar el tributo mediante la función investigadora, y de igual modo cuando la declaración-autoliquidación se ha presentado pero lo ha sido de modo no veraz o incompleto".

16 Piénsese en el Impuesto sobre la Renta de las Personas Físicas, el Impuesto sobre Sociedades y el Impuesto sobre el Valor Añadido, principalmente.

17 Vid.: Aníbarro Pérez, S.: La interpretación razonable de la norma como eximente de la responsabi-

176 lidad por infracción tributaria, Lex Nova, Valladolid, 1999, p. 99. 
actual LGT de 2003. Mediante la afirmación con carácter general de la buena fe a cargo del obligado por un tributo, debía ser la Administración la que probara la concurrencia de la culpabilidad en la comisión de infracciones tributarias. Sin embargo, a pesar de su supresión, se puede considerar que la buena fe se encuentra subsumida en la presunción de inocencia establecida en el art. 24 de la Constitución Española y que rige el ordenamiento administrativo sancionador.

En segundo término se puede advertir que podría haberse introducido como causa eximente de responsabilidad el hecho de que la declaración sea elaborada por la Administración tributaria o por entidades colaboradoras, cuestión bastante frecuente en la práctica; en efecto, si a resultas de dicha actuación surgen inexactitudes o se da lugar a una infracción tributaria, el sujeto pasivo no podrá alegar su elaboración por dichos órganos o sujetos privados, con lo que se verá sometido a una hipotética sanción por una conducta que no ha cometido. Evidentemente, se podría pensar que estaríamos ante una comisión culposa al no haber prestado la diligencia debida, pero también se puede argumentar que el presunto infractor ha obrado de acuerdo al parecer de la propia Administración o de una entidad colaboradora de ella misma.

Sin embargo, la norma, como hemos analizado, solo no impone una sanción en el caso de contestaciones a consultas ante la propia Administración, pero nada se dice respecto a las actuaciones de colaboración con los contribuyentes, como es la de elaborar declaraciones o prestar asistencia técnica para ello; todavía peor es el caso de las entidades colaboradoras, pues no tienen la consideración de órgano público y por lo tanto no surge ni siquiera el interrogante que nos planteamos ${ }^{18}$.

Fuera del apartado 2 del art. 179 de la LGT se hallan otros casos de ausencia o de disminución de la responsabilidad de los hipotéticos sujetos infractores, como es el caso del apartado 3 del mismo precepto, que prevé su atenuación si regularizan su "situación tributaria o subsanen las declaraciones, autoliquidaciones, comunicaciones de datos o solicitudes presentadas con anterioridad de forma incorrecta".

Para aclarar esta posibilidad el RGRST desarrolla lo que se entiende por regularización voluntaria, cuando en su art. 2 considera por tal "la efectuada antes de la notificación de un requerimiento para el cumplimiento de la obligación tributaria o de la notificación del inicio de un procedimiento de comprobación o investigación o de un procedimiento sancionador" $"$. Además, los arts. 14 y 15 del citado Reglamento mati-

18 Pueden considerarse a dichas entidades como realizadoras de una labor de asesoría fiscal, al igual que cualquier otro sujeto particular que se dedique a la confección de autoliquidaciones o deberes tributarios. Por el contrario, se podría incluso plantear para los supuestos en los que es la Administración tributaria la que realiza las actuaciones, la petición de indemnización por funcionamiento anormal de los servicios públicos. Esta temática, como es lógico, excede los límites del presente estudio.

19 Como indican Aníbarro Pérez, S. y Sesma Sánchez, B.: "a este respecto, es posible advertir que para que la actuación de la Administración pueda entenderse que inhibe la voluntariedad de una posterior actuación del obligado tributario tendente a la regularización de su situación es preciso que entre una y 
zan el momento preciso y las declaraciones a presentar para poder ampararse en dicha regularización ${ }^{20}$.

Cuestión distinta es la conformidad o no del sujeto infractor con la sanción propuesta por la Administración tributaria, que entra dentro del terreno de la extinción de la responsabilidad, pero no es una auténtica causa eximente; de ahí que la abordemos al analizar dicha extinción.

Para terminar este epígrafe relativo a los principios de la potestad sancionadora en el campo fiscal, resta referirnos, a la no concurrencia de sanciones tributarias y a la irrectroactividad de la mismas. Veamos cada una por separado.

El principio de no concurrencia se prevé expresamente en el art. 180 de la LGT, cuyo análisis podemos dividir en tres bloques:

En primer lugar, en el apartado 1 del art. 180 se regula la obligatoriedad que tiene la Administración tributaria para pasar a la jurisdicción competente el expediente correspondiente si se estiman indicios de que una infracción pueda ser constitutiva de delito contra la Hacienda Pública; en este caso, el procedimiento administrativo queda suspendido en espera de la resolución del Tribunal. Si se llega a una sentencia condenatoria, ello significará la ausencia de sanción administrativa y si se archiva la causa, se proseguirá con el procedimiento tributario en el momento en que se hubiese suspendido.

Esta primera parte del precepto resume, pues, el principio de non bis in idem, que, como es bien sabido, obliga a no encausar por un mismo hecho en dos instancias diferentes: administrativa y jurisdiccional; esto nos pone en relación con el segundo apartado del artículo, en el que se prohíbe que una misma acción u omisión que deba

\footnotetext{
otra -la actuación de la Administración y la posterior del sujeto- exista un nexo de causalidad”. (Vid.: “Capítulo VII. Infracciones y sanciones tributarias y procedimiento", en la Obra Colectiva: Los nuevos reglamentos tributarios, Thomson-Civitas, Navarra, 2006, pp. 275 y 276). A este respecto se puede traer a colación la Sentencia del Tribunal Superior de Justicia de Valencia, de 17 de enero de 2003 (Jurisprudencia Tributaria, $2004,3)$ en la que se lee lo siguiente: “(...) ambos elementos, requerimiento y declaración complementaria, aunque referidos al mismo impuesto y período, no están causalmente vinculados, ni tienen relación alguna, ya que se refieren a materias radicalmente distintas. De esta forma, al quedar desconectado el requerimiento de la liquidación complementaria, carece aquél del efecto intimidatorio propio del mismo, y consiguientemente la conducta del actor no puede sancionarse como la hace la administración (...)".

20 Así el art. 14 del RGRST indica que "no se impondrá la sanción que resulte por la presentación fuera de plazo de la autoliquidación o declaración exclusivamente en relación con los datos que hubiesen sido correctamente declarados en plazo", mientras que el art. 15, apartado 5 establece: "Cuando se presenten voluntariamente sin requerimiento previo declaraciones o autoliquidaciones que subsanen las presentadas con anterioridad de forma incorrecta, si la nueva declaración o autoliquidación se presenta conteniendo datos incompletos, inexactos o falsos, se impondrá la sanción que proceda según lo dispuesto en el artículo 199 de la Ley 58/2003, de 17 de diciembre, General Tributaria, exclusivamente en relación con los nuevos datos incorrectamente presentados"; finalmente, el apartado 6 del citado art. 15 prescribe: "No se incurrirá en responsabi178 lidad por la contestación incorrecta a un requerimiento cuando se presente voluntariamente, sin nuevo reque rimiento, una nueva contestación que subsane la presentada con anterioridad".
} 
aplicarse como criterio de graduación -de los que nos ocuparemos posteriormente en este estudio- no pueda ser sancionada como infracción independiente ${ }^{21}$.

Por último, en tercer lugar, la realización de varias acciones u omisiones constitutivas de varias infracciones posibilitará la imposición de sanciones por todas ellas ${ }^{22}$, mientras que el apartado 4 del art. 180 establece que las sanciones serán compatibles con la exigencia del interés de demora y de los recargos del período ejecutivo; con ello se prevén los supuestos de concurso real de infracciones, de modo similar al Derecho Penal.

En cuanto a la irretroactividad, el art. 178 de la LGT la menciona al indicar que "el principio de irretroactividad se aplicará con carácter general, teniendo en consideración lo dispuesto en el apartado 2 del artículo 10 de esta ley". Dicho art. 10-2 se refiere expresamente a que "las normas que regulen el régimen de infracciones y sanciones tributarias y el de los recargos tendrán efectos retroactivos respecto de los actos que no sean firmes cuando su aplicación resulte más favorable para el interesado". Como se deduce fácilmente, al permitir el efecto retroactivo para la regulación más favorable en este terreno, se está admitiendo la irretroactividad para los supuestos en que no se tenga tal carácter beneficioso, de tal manera que a la entrada en vigor de la nueva LGT, evento que se produjo el 1 de julio de 2004, todas las infracciones y sanciones que no fuesen firmes, acudieron a la LGT de 2003 si tuviesen mejor carácter para el sujeto ${ }^{23}$.

21 Hernanz Martín, A. sintetiza lo dicho en el texto del viejo axioma penalista del non bis in idem considerando que se puede manifestar de dos formas: externa e interna; externa, al establecerse la precedencia y preferencia de la autoridad judicial penal sobre la Administración -como no podía ser de otra forma- a la hora de sancionar una misma conducta e, interna, cuando en el ámbito administrativo, la sanción por un determinado hecho se debe blindar para no ser de nuevo sancionado por el mismo. (Vid.: "Las sanciones en la Ley General Tributaria y en el Reglamento Sancionador”, ob. cit., pp. 61 y 62).

22 Simón Acosta, E. matiza lo indicado en la norma cuando escribe: "Salvados los casos de concurso de leyes, la concurrencia de infracciones determina, como acabamos de decir, la necesidad de sancionarlas todas. Cada incumplimiento legalmente tipificado es una infracción distinta y habrá tantas infracciones como incumplimientos, con independencia de que dichos incumplimientos sean descubiertos o comprobados en uno solo o en varios procedimientos o expedientes administrativos distintos. Esta regla se encuentra reflejada, con exceso de detalle, en el artículo 3 del RGRST. Lo esencial es la infracción consumada y no la unidad o pluralidad de procedimientos administrativos en los que dicha infracción sea objeto de tratamiento... Para ello se establece que en cada procedimiento sancionador que se incoe se impondrá la sanción que hubiese procedido de mediar un solo procedimiento de aplicación de los tributos, minorada en el importe de las sanciones impuestas en los procedimientos sancionadores anteriores". (Vid.: "Capítulo IX. La potestad sancionadora", ob. cit., p. 848).

23 Para concretar el carácter transitorio de esta medida, la Disposición Transitoria Cuarta de la LGT en su apartado 1 prevé lo siguiente: "Esta ley será de aplicación a las infracciones tributarias cometidas con anterioridad a su entrada en vigor, siempre que su aplicación resulte más favorable para el sujeto infractor y la sanción impuesta no haya adquirido firmeza.

La revisión de las sanciones no firmes y la aplicación de la nueva normativa se realizará por los órganos administrativos y jurisdiccionales que estén conociendo de las reclamaciones y recursos, previa audiencia al interesado".

Para un mayor detalle en este tema de la irretroactividad, vid.: Hermosín, M.: Procedimiento Sancionador Tributario. Cuestiones Problemáticas, ob. cit., pp. 251 y ss. 


\section{SUJETOS INTERVINIENTES EN LAS INFRACCIONES Y SANCIONES TRIBUTARIAS}

Bajo este rótulo nos vamos a ocupar muy brevemente de los sujetos que la LGT considera como posibles infractores objeto de ulteriores sanciones tributarias; como es lógico, también participan en este proceso los órganos de la Administración tributaria encargados del procedimiento sancionador, al que nos referiremos posteriormente en este trabajo.

El art. 181 de la LGT realiza una enumeración de quién puede considerarse como sujeto infractor, considerando como tal a las personas físicas o jurídicas y las entidades sin personalidad jurídica que menciona el art. 35-4 de la LGT, que realicen las acciones u omisiones tipificadas como tales en las leyes. Esta previsión legal merece algunas consideraciones.

En primer lugar, las entidades sin personalidad jurídica del art. 35-4 de la LGT son las "herencias yacentes, comunidades de bienes y demás entidades que (...) constituyan una unidad económica o un patrimonio separado susceptibles de imposición". En consecuencia, se establece un elenco muy amplio de los posibles infractores tributarios.

Una segunda consideración se refiere al art. 181-1 de la LGT, el cual realiza una enumeración ejemplificativa -como se deduce de la expresión entre otros- de dichos sujetos y que, en gran medida, coincide con la que realiza el art. 35 del mismo cuerpo legal al referirse a los obligados tributarios ${ }^{24}$.

Otro aspecto relevante a destacar es la declaración como solidaria de la obligación de pagar la sanción correspondiente si existen varios sujetos que concurran en la misma infracción, como preceptúa el apartado 3 del art. 181 de la LGT, de manera similar a lo que sucede frente a la obligación tributaria derivada de un gravamen (art. 35-6 de la LGT).

Finalmente y para terminar este apartado hay que llamar la atención sobre el hecho de que se permite sancionar tanto a personas físicas como a personas jurídicas o sociedades; para estas últimas, además, el art. 182-3 de la LGT, admite que se transmita

24 Dice el art. 181-1: "Serán sujetos infractores las personas físicas o jurídicas y las entidades mencionadas en el apartado 4 del artículo 35 de esta ley que realicen las acciones u omisiones tipificadas como infracciones en las leyes. Entre otros, serán sujetos infractores los siguientes:

a) Los contribuyentes y los sustitutos de los contribuyentes.

b) Los retenedores y los obligados a practicar ingresos a cuenta.

c) Los obligados al cumplimiento de obligaciones tributarias formales.

d) La sociedad dominante en el régimen de consolidación fiscal.

e) Las entidades que estén obligadas a imputar o atribuir rentas a sus socios o miembros.

180 butario".

f) El representante legal de los sujetos obligados que carezcan de capacidad de obrar en el orden tri- 
la responsabilidad a sus sucesores ${ }^{25}$-liquidadores $u$ otras sociedades-, a diferencia de lo que sucede con las personas físicas que, como comprobaremos al abordar la extinción de las infracciones y sanciones, desaparece con la muerte del sujeto infractor.

\section{LAS INFRACCIONES TRIBUTARIAS}

\section{Concepto}

El art. 183-1 de la LGT ofrece una definición de infracciones tributarias como "las acciones u omisiones dolosas o culposas con cualquier grado de negligencia que estén tipificadas y sancionadas como tales en esta u otra ley".

Como se comprueba de la atenta lectura del precepto, varias son las características de una infracción tributaria y que podemos exponer del modo siguiente:

En primer lugar se trata de una conducta de carácter positivo o negativo, como se desprende del inciso "acciones u omisiones", de tal modo que se está pensando claramente en el supuesto de ausencia de actividad por parte de los sujetos pasivos de un gravamen, tal como la no presentación de declaraciones o autoliquidaciones pertinentes.

En segundo término se concreta el principio de responsabilidad que ya analizamos anteriormente, pero no cualquier tipo de responsabilidad, puesto que al mencionar el carácter doloso o culposo, aunque sea con cualquier grado de negligencia se está obviando una de carácter objetivo, por lo que siempre hará falta una mínima intervención de la voluntad o de la actitud del sujeto infractor.

Por último, el precepto citado se refiere a la tipicidad de las infracciones, que deben estar contenidas en la LGT o en cualquier otra normativa, como sucede con las de contrabando, que se prevé en el apartado 3 del aludido art. 183 de la LGT que se "regirán por su normativa específica", temática que excede los límites de este estudio ${ }^{26}$.

25 Como opina Simón Acosta, E.: "El fundamento de la transmisibilidad de las sanciones de las personas jurídicas es el mismo que hemos señalado antes para justificar su imputabilidad: la sociedad es una persona ficta, una creación del Derecho para encauzar la actividad de las personas naturales que son las que soportan, en su patrimonio, los efectos de las sanciones pecuniarias impuestas a la persona jurídica. No es razonable que el sucesor de la persona jurídica se enriquezca mientras no estén satisfechas las responsabilidades pecuniarias en que haya incurrido la persona jurídica por la comisión de infracciones". (Vid.: “Capítulo IX. La potestad sancionadora”, ob. cit., p. 831).

El art. 40-5 de la LGT, cuando se refiere a los sucesores de las personas jurídicas y de entidades sin personalidad que mencionábamos más arriba en el texto, establece que las sanciones tributarias se exigirán a los citados sucesores "hasta el límite del valor de la cuota de liquidación que les corresponda", lo que supone un tope para cada uno de ellos, lo que puede dar lugar a supuestos en que no se cubra el total de la sanción y nos permite afirmar que, en ocasiones, la sanción no se sufragará en la cuantía íntegra y se perderá parte de la misma.

26 Dicha regulación consiste en la Ley Orgánica 12/1995, de 12 de diciembre, de Represión del Contrabando, en la que se contienen los delitos penales y las infracciones administrativas sobre esta cuestión, 
En definitiva, la conceptuación que ofrece la LGT no ofrece lugar a dudas sobre el carácter y la calificación de las infracciones tributarias; cuestión aparte supone la clasificación o calificación de las mismas que estudiamos seguidamente.

\section{Tipificación en la Ley General Tributaria}

A la hora de clasificar las infracciones tributarias, el art. 183-2 de la LGT establece una división tripartita entre leves, graves y muy graves, de modo similar a las de carácter administrativo ${ }^{27}$ y para distinguir entre ellas, el art. 184 del mismo cuerpo legal las califica de tal forma remitiéndose a la tipificación contenida en los artículos 191 a 206 de la LGT, advirtiéndose que cada infracción se subsumirá en la categoría correspondiente con carácter unitario ${ }^{28}$. En consecuencia, habrá que comprobar para cada una de las infracciones tipificadas en dichos preceptos si son leves, graves o muy graves, cuyos criterios para realizar tal distinción difieren de unas a otras ${ }^{29}$. En el caso de concurrencia de múltiples circunstancias determinantes en varias infracciones, el art. 9-1 del RGRST establece que "se tomará en consideración la que determine una mayor gravedad de la conducta".

y el Real Decreto 1649/1998, de 24 de julio, por la que se desarrolla el Título II de la Ley Orgánica anterior, en relación con las infracciones administrativas de contrabando.

También podemos mencionar, a título de ejemplo, la Ley 38/1992, de 28 de diciembre, de Impuestos Especiales, en la que se contemplan infracciones y sanciones propias del régimen jurídico de este tipo de gravámenes; así, los arts. 19, 35, 45, 55 y 87 de dicha norma contienen las correspondientes a los Impuestos Especiales de Fabricación y el art. 72 las de del Impuesto Especial sobre Determinados Medios de Transporte; no obstante y de modo similar a la LGT, el art. 19 de la Ley 38/1992 establece, en su apartado 1 que "EI régimen de infracciones y sanciones en materia de impuestos especiales de fabricación se regirá por lo dispuesto en la Ley General Tributaria, en las normas específicas que para cada uno de estos impuestos se establecen en esta ley y en las contenidas en los siguientes apartados". Es decir, siempre tendrán carácter y aplicación general las disposiciones incluidas en la LGT.

27 Como indica Simón Acosta, E.: “La LGT se aparta de la tradicional clasificación de las infracciones tributarias (simples, de omisión y de defraudación hasta 1985 y simples y graves desde esa fecha hasta 2003) para acomodarse a lo dispuesto por el artículo 129.1 de la LRJ-PAC... Se aprecia en el texto de la ley que la clasificación de las infracciones tributarias en leves, graves y muy graves ha sido introducida forzadamente, pues ni aparecen claros los criterios determinantes de la mayor o menor gravedad de la conducta, ni son muchas las consecuencias de la inclusión de la infracción en una de esas categorías. No existe un catálogo de sanciones para cada clase de infracciones, por lo que no existe un paralelismo entre la escala de gravedad y la cuantía de la sanción. Tampoco es aquí aplicable la diferencia de período de prescripción establecida por el artículo 132 de la LRJ-PAC según las distintas clases". (Vid.: "Capítulo IX. La potestad sancionadora", ob. cit., p. 856).

28 Como escriben Aníbarro Pérez, S. y Sesma Sánchez, B.: “... dado que se opta por una calificación unitaria y no plural, no cabe fragmentar la conducta infractora, sino que ésta debe ser analizada en su conjunto, lo cual plantea el problema de qué ocurre cuando en relación con una misma conducta infractora concurran diversas circunstancias que puedan determinar diferentes calificaciones de la infracción". (Vid.: “Capítulo VII. Infracciones y sanciones tributarias y procedimiento”, en la Obra Colectiva: Los nuevos reglamentos tributarios, Thomson-Civitas, Navarra, 2006, p. 287).

29 A nuestro parecer, la regulación en la anterior LGT de 1963 suponía una nota de mayor sencillez y seguridad jurídica -en contra del parecer de la Exposición de Motivos de la nueva LGT de 2003-, puesto que la división entre infracciones simples y graves se hacía sobre la base del perjuicio económico 182 el texto. 
Con carácter general, el art. 184 de la LGT se ocupa de exponer dos criterios a los que se remiten continuamente las infracciones de los arts. 191 y ss. de la misma norma; se trata de la ocultación de datos y de la presencia de medios fraudulentos.

La ocultación de datos se define en el apartado 2 del art. 184 de la LGT como el supuesto en que "no se presenten declaraciones en las que se incluyan hechos u operaciones inexistentes o con importes falsos, o en las que se omitan total o parcialmente operaciones, ingresos, rentas, productos, bienes o cualquier otro dato que incida en la determinación de la deuda tributaria, siempre que la incidencia de la deuda derivada de la ocultación en relación con la base de la sanción sea superior al 10 por 100". Este apartado merece algunos comentarios de interés.

En primer lugar, supone una conducta positiva y negativa, ya que se aplica tanto para la presentación de declaraciones tributarias erróneas -siempre con un elemento de dolo o culpa- en las que se omitan datos o se falseen los mismos, o para la ausencia de presentación de declaraciones, con lo que estaríamos ante una comisión por omisión.

En segundo término, es necesario que las actuaciones aludidas den lugar a alteraciones en la cuantificación de la deuda tributaria superiores al 10 por 100 en relación con la base de la sanción, es decir, con el importe dejado de ingresar o de declarar a consecuencia de la infracción cometida. Si no se supera dicho importe, no podrá utilizarse este criterio de calificación de infracciones ${ }^{30}$ y para concretar este método de cálculo el art. 10 del RGRST establece una fórmula matemática que intenta de este modo objetivar el sistema y así tratar de respetar el principio de seguridad jurídica ${ }^{31}$. A nuestro parecer, se está ofreciendo una complejidad innecesaria en aras a dicha seguridad.

En cuanto a la presencia de medios fraudulentos, el apartado 3 del art. 184 de la LGT considera que se produce tal eventualidad en tres supuestos distintos ${ }^{32}$ :

30 Debe observarse que los criterios que analizamos en el texto se emplean para calificar, en cada tipo de infracción, si son leves, graves o muy graves, pero no como un medio de graduación de la cuantificación de las sanciones que les correspondan; para ello se utilizan otros métodos como examinaremos en el siguiente epígrafe de este estudio.

31 Dicho art. 10 del RGRST tiene el siguiente tenor literal: “1. La incidencia de la deuda derivada de la ocultación sobre la base de la sanción se determinará por el coeficiente regulado en el apartado 2.

2. El coeficiente a que se refiere el apartado anterior se determinará multiplicando por 100 el resultante de una fracción en la que figuren:

a) En el numerador, la suma del resultado de multiplicar los incrementos realizados en la base imponible o liquidable en los que se haya apreciado ocultación por el tipo de gravamen del tributo, si dichos incrementos se producen en la parte de la base gravada por un tipo proporcional o, si se producen en la parte de la base gravada por una tarifa, por el tipo medio de gravamen resultante de su aplicación, más los incrementos realizados directamente en la cuota del tributo o en la cantidad a ingresar en los que se haya apreciado ocultación.

b) En el denominador, la suma del resultado de multiplicar todos los incrementos sancionables que se hayan regularizado en la base imponible o liquidable por el tipo de gravamen del tributo, si dichos incrementos se producen en la parte de la base gravada por un tipo proporcionalo, si se producen en la parte de la base gravada por una tarifa, por el tipo medio de gravamen resultante de su aplicación, más los incrementos sancionables realizados directamente en la cuota del tributo o en la cantidad a ingresar".

32 De nuevo, el RGRST regula el cálculo de la incidencia de este criterio sobre la base de la sanción en los arts. 11 y 12, de modo similar al expuesto en la nota a pie de página anterior, por lo que ahorramos su cita literal en este momento. 
Primero.-Existencia de anomalías sustanciales en la contabilidad y en los libros o registros establecidos por la normativa tributaria33; en este sentido la propia norma trata de aclarar dicho concepto jurídico indeterminado, al indicar que "se consideran anomalías sustanciales: $10^{\circ}$ El incumplimiento absoluto de la obligación de llevanza de la contabilidad o de los libros o registros establecidos por la normativa tributaria.

2. La llevanza de contabilidades distintas que, referidas a una misma actividad y ejercicio económico, no permitan conocer la verdadera situación de la empresa.

3. La llevanza incorrecta de los libros de contabilidad o de los libros o registros establecidos por la normativa tributaria, mediante la falsedad de asientos, registros o importes, la omisión de operaciones realizadas o la contabilización en cuentas incorrectas de forma que se altere su consideración fiscal. La apreciación de esta circunstancia requerirá que la incidencia de la llevanza incorrecta de los libros o registros represente un porcentaje superior al 50 por 100 del importe de la base de la sanción".

Segundo.-Empleo de facturas, justificantes u otros documentos falsos o falseados, cuando su incidencia represente un porcentaje superior al 10 por 100 de la base de la sanción ${ }^{34}$.

Tercero.-Utilización de personas o entidades interpuestas cuando el infractor haya hecho figurar a nombre de un tercero, con o sin su consentimiento, la titularidad de bienes, derechos, rentas, ganancias o realización de operaciones con trascendencia tributaria de las que se deriva la infracción de que se trate.

Retomando el hilo conductor de este epígrafe, resta enumerar, pues resultaría imposible abordarlas con detalle en el marco del presente estudio, las dieciséis infracciones tributarias que regula la LGT en sus arts. 191 a 20635; para ello, enunciaremos su contenido esencial, la base sobre la que girará la posible sanción y los principales elementos de calificación de cada una de ellas para que se cataloguen como leves, graves o muy graves ${ }^{36}$.

33 Véase el art. 29 del Real Decreto 1065/2007, de 27 de julio, por el que se aprueba el Reglamento General de las actuaciones y los procedimientos de gestión e inspección tributaria y de desarrollo de las normas comunes de los procedimientos de aplicación de los tributos, en el que se definen la obligaciones de llevanza de libros-registro mencionadas en el texto.

34 En este sentido el apartado 2 del art. 4 del RGRST desarrolla lo que se entiende por operaciones o facturas o documento falsos, acudiendo a su mención como de naturaleza distinta de las reales, siempre, eso sí, que hayan sido instrumento para la comisión de la infracción correspondiente.

35 La LGT se refiere en su Capítulo III a la Clasificación de las infracciones y sanciones tributarias, si bien el título pensamos que es engañoso, ya que no se realiza ninguna clasificación propiamente dicha, sino que se limita a describir cada una de manera secuencial, sin ningún tipo de método de división o de agrupamiento entre ellas. Quizá se podría interpretar que sigue un criterio de mayor a menor gravedad de las conductas ilícitas, ya que parte de infracciones por dejar de ingresar cantidades y termina con las relativas a deberes informativos; en todo caso, hubiese sido preferible que se comentara expresamente el criterio para la enumeración o la justificación del mismo.

36 Dejamos para el siguiente epígrafe de este estudio la sanción correspondiente a cada una de 
Primera (art. 191 LGT): dejar de ingresar la deuda tributaria que debiera resultar de una autoliquidación, supuesto típico de fraude fiscal, tomándose como base de la sanción la cantidad dejada de ingresar. Los criterios para calificarla dependen de su cuantía, normalmente hasta 3.000 euros para ser leve y si ha habido ocultación o mecanismos fraudulentos, tal como los hemos definido anteriormente. Si se exceden las cantidades se tratará de una infracción grave o muy grave para los medios fraudulentos.

Segunda (art. 192 LGT): incumplir la obligación de presentar de forma completa y correcta declaraciones o documentos necesarios para practicar liquidaciones, tomándose como base de la sanción la diferencia que resulte de la adecuada liquidación del tributo y la que hubiera procedido de acuerdo con los datos declarados. Será leve si no excede de 3.000 euros o no ha habido ocultación y grave o muy grave si concurren los mismos criterios indicados para la infracción anterior.

Tercera (art. 193 LGT): obtener indebidamente devoluciones; se trata de devoluciones tributarias propias de cada gravamen, como sucede, por ejemplo, con el Impuesto sobre la Renta de las Personas Físicas o con el Impuesto sobre el Valor Añadido. La base de la sanción será la cantidad devuelta sin derecho a ello y la diferenciación entre leve, grave o muy grave es igual a la efectuada para los supuestos de infracción anteriores.

Cuarta (art. 194 LGT): solicitud indebida de devoluciones, beneficios o incentivos fiscales; en este caso, ya no se trata de haber obtenido la cantidad de manera ilícita, sino de falsear los datos necesarios para pedirla o para disfrutar de beneficios fiscales, como exenciones o deducciones fiscales. La infracción se califica, a diferencia de las anteriores, solamente como grave y como base de la sanción se tomará la cantidad indebidamente solicitada (que no percibida, ya que si no, consistiría en la tercera infracción).

Quinta (art. 195 LGT): determinación o acreditación improcedente de partidas positivas o negativas o créditos tributarios aparentes. La base de la sanción será la cantidad improcedentemente atribuida y la infracción se califica como grave. Se trata de partidas que den origen a declaraciones tributarias diferentes a las que corresponderían en realidad.

Sexta (art. 196 LGT): imputación incorrecta de bases imponibles, rentas o resultados por entidades sometidas a un régimen de imputación de rentas; en este caso, se trata de entidades en dicho régimen, principalmente las entidades sin personalidad del art. 35-4 de la LGT, a las que ya nos hemos referido al tratar de los sujetos infractores. La base de la sanción es la cuantía que se ha atribuido de manera irregular a los socios, partícipes o comuneros de tales entidades, calificándose la infracción únicamente como grave.

Séptima (art. 197 LGT): imputación incorrecta de deducciones, bonificaciones o pagos a cuenta en las entidades en régimen de imputación de rentas; supuesto muy 
similar al anterior, solo que en vez de incidir sobre bases imponibles, se refiere a las cantidades a descontar sobre la cuota tributaria. Coincide con ella en la base de la sanción y en su carácter grave.

Octava (art. 198 LGT): no presentación en plazo de declaraciones o autoliquidaciones sin que se produzca perjuicio económico a la Hacienda Pública por ello o por no comunicar el domicilio fiscal o las condiciones de algunas autorizaciones; se trata ya de casos en los que a resultas de la comisión de la conducta, no se ha producido un menoscabo al erario público, es decir, no se ha producido un beneficio fiscal no justificado para el sujeto infractor. Sin embargo, se ha dejado de cumplir con algunos deberes tributarios o se ha cometido alguna irregularidad en los plazos correspondientes para cumplir con los mismos. La infracción se califica siempre como leve.

Novena (art. 199 LGT): presentación incorrecta de declaraciones o autoliquidaciones sin perjuicio económico para la Hacienda Pública. En este supuesto, la diferencia con la anterior conducta estriba en que ahora se ha presentado en plazo el deber correspondiente, pero se ha hecho de forma no adecuada, es decir, mediante datos falsos, inexactos o incompletos; siempre eso sí, que no se produzca una disminución de la cantidad a contribuir en concepto de tributo. En esta ocasión la infracción se califica como grave.

Décima (art. 200 LGT): incumplimiento de obligaciones contables y registrales; con esta infracción se inician las relativas a las irregularidades en los deberes formales de documentación inherentes a los tributos. Aquí, como se deduce fácilmente, esta conducta, así como muchas de las siguientes, son también un medio para calificar un ilícito como medio fraudulento, por lo que todo ello conduce a una cierta complejidad y a riesgo de duplicidad de sanción por el mismo hecho. Para evitar esta situación, como ya hemos examinado, el art. 180-2 de la LGT prescribe que una misma acción u omisión que deba aplicarse como criterio de graduación de una infracción o como circunstancia de calificación como grave o muy grave, no podrá ser sancionada de forma independiente. En definitiva, se declara la precedencia de estos criterios como medios de graduación, más que en forma de ilícitos autónomos. Si se entiende que es una infracción, subsumida en este art. 200 de la LGT, se considera siempre como grave.

Undécima (art. 201 LGT): incumplimiento de obligaciones de facturación o documentación, relativas a la expedición, remisión, rectificación y conservación de las mismas. Podemos considerar reproducidas aquí las observaciones realizadas en el supuesto anterior, con la salvedad de que se puede calificar como infracción grave o leve, en función de su cuantía o la dimensión del incumplimiento.

Duodécima (art. 202 LGT): incumplimiento de obligaciones relativas a la utilización y a la solicitud del número de identificación fiscal (NIF) o de otros números o códigos. Podrá ser leve si se trata de sujetos particulares, grave si son entidades de crédi186 to o muy grave si se trata de comunicar datos falsos para solicitar los números de 
identificación fiscal provisionales o definitivos; esto último está pensado principalmente para el caso de personas jurídicas.

Decimotercera (art. 203 LGT): resistencia, obstrucción, excusa o negativa a las actuaciones de la Administración tributaria. La norma trata de definir qué se entiende por tal, principalmente si se han notificado las actuaciones al sujeto infractor y éste ha dilatado, entorpecido o impedido las mismas, ya sea en el marco de un procedimiento inspector o de otras circunstancias de la gestión fiscal ${ }^{37}$. La infracción se califica en el precepto como grave.

Decimocuarta (art. 204 LGT): incumplimiento del deber de sigilo exigido a los retenedores y a los obligados a realizar ingresos a cuenta. Se califica como grave y entra dentro de la esfera de la intimidad personal y de la inviolabilidad de las comunicaciones, de acuerdo con el art. 18 de la Constitución Española. Evidentemente tiene que tratarse de conductas y de datos relevantes, pues de otro modo no se generaría el perjuicio que la ley trata de impedir.

Decimoquinta (art. 205 LGT): incumplimiento de la obligación de comunicar correctamente datos al pagador de rentas sometidas a retención o ingreso a cuenta; en este caso, se está pensando principalmente en los perceptores de rendimientos del trabajo en el Impuesto sobre la Renta de las Personas Físicas, calificándose como leve o muy grave, en función de si el sujeto retenido tenga o no la obligación de presentar la declaración por el gravamen correspondiente. Como base de la sanción se calculará la diferencia entre lo efectivamente retenido y lo que debió hacerse correctamente.

Decimosexta (art. 206 LGT): incumplimiento de la obligación de entregar el certificado de retenciones o ingresos a cuenta; de nuevo se incide sobre conductas relativas a los deberes de efectuar pagos a cuenta en los impuestos sobre la renta. Ahora se trata de una conducta del pagador, que debe entregar dicho certificado al preceptor de un rendimiento. La infracción se califica como leve.

\section{LAS SANCIONES TRIBUTARIAS}

\section{Tipificación}

Antes de abordar la diversa tipología de sanciones presentes en la LGT, hay que advertir acerca de una cuestión importante que consiste en que, en la nueva regula-

37 El apartado 1 del art. 203 de la LGT entiende, entre otras, que se producen las conductas ilícitas en los siguientes supuestos: “ a) No facilitar el examen de documentos, informes, antecedentes, libros, registros, ficheros, facturas, justificantes y asientos de contabilidad principal o auxiliar, programas y archivos informáticos, sistemas operativos y de control y cualquier otro dato con trascendencia tributaria.

b) No atender algún requerimiento debidamente notificado.

c) La incomparecencia, salvo causa justificada, en el lugar y tiempo que se hubiera señalado.

d) Negar o impedir indebidamente la entrada o permanencia en fincas o locales a los funcionarios de la Administración tributaria o el reconocimiento de locales, máquinas, instalaciones y explotaciones relacionados con las obligaciones tributarias.

e) Las coacciones a los funcionarios de la Administración tributaria". 
ción de 2003, se ha cambiado el criterio contenido en la anterior LGT de 1963 en el sentido de separar las sanciones tributarias del resto de componentes de la deuda tributaria; en efecto, el vigente art. 58 de la LGT de 2003 no incluye entre las posibles partes integrantes de la deuda tributaria a las sanciones, como sí ocurría en la normativa de 1963, por lo que no les son aplicables los criterios y principios de la misma ${ }^{38}$. La causa no es otra que separar ambos regímenes, como sucede, por ejemplo, con las causas de extinción de las sanciones o del procedimiento sancionador.

Entrando ya en las clases de sanciones que pueden aplicarse, el art. 185 de la LGT la divide en pecuniarias y no pecuniarias de carácter accesorio; a su vez, las pecuniarias pueden consistir en una multa fija o en una multa proporcional.

Respecto a las pecuniarias, al tratarse de una multa, habrá que estar a la cuantía correspondiente que establecen los arts. 191 a 206 para cada una de las infracciones tributarias que exponíamos en el epígrafe anterior y de las que daremos noticia seguidamente. En cuanto a las no pecuniarias, el art. 186 de la LGT prescribe su imposición en algunos supuestos, haciéndolo depender del importe de la cuantía de la multa correspondiente y del carácter grave o muy grave de la infracción.

Así, el citado art. 186 prevé dos situaciones para aplicar sanciones no pecuniarias de carácter accesorio:

En primer lugar, si se trata de una infracción grave o muy grave y la multa pecuniaria ha sido igual o superior a 30.000 euros, aplicándose a su vez el criterio de graduación de sanciones consistente en la comisión repetida de infracciones tributarias ${ }^{39}$, el apartado 1 de dicho precepto establece la posible imposición de lo siguiente:

Primero: la pérdida del derecho a obtener subvenciones o ayudas públicas y del derecho a aplicar beneficios e incentivos fiscales de carácter rogado durante el plazo de una año para una infracción grave o de dos años si es muy grave.

Segundo: la prohibición de contratar con la Administración pública que hubiera impuesto la sanción durante el plazo de un año para infracción grave o dos años si es muy grave.

En segundo término, si es una infracción muy grave y la multa pecuniaria fue igual o superior a 60.000 euros, utilizándose el criterio de graduación de comisión repetida de infracciones tributarias, las sanciones accesorias indicadas se pueden extender hasta cinco años, dependiendo de la cuantía y gravedad de la multa impuesta.

38 El apartado 3 del art. 58 de la LGT establece: "Las sanciones tributarias que puedan imponerse de acuerdo con lo dispuesto en el título IV de esta ley no formarán parte de la deuda tributaria, pero en su recaudación se aplicarán las normas incluidas en el capítulo V del título III del esta ley".

39 De este criterio de graduación, así como de los demás contenido en la ley nos ocupamos en el siguiente epígrafe de este apartado del trabajo. 
En tercer lugar, el art. 186 prevé la sanción no pecuniaria de la suspensión del ejercicio de profesiones oficiales, cargo o empleo público de tres a doce meses, si se han vulnerado los deberes de colaboración previstos en la legislación fiscal y se ha incurrido en la infracción correspondiente, tal como las definimos en el epígrafe anterior de este trabajo ${ }^{40}$.

Pasando a enumerar las diferentes sanciones pecuniarias previstas en cada una de las 16 infracciones tributarias podemos esquematizarlas del modo siguiente, de manera similar a como las enunciamos al examinarlas al exponer su tipología:

Primera (art. 191 LGT): dejar de ingresar la deuda tributaria que debiera resultar de una autoliquidación. La sanción para las infracciones leves y graves podrá ser del 50 al 100 por 100 de la base correspondiente, mientras que para las muy graves oscilará entre el 100 y el 150 por 100.

Segunda (art. 192 LGT): incumplir la obligación de presentar de forma completay correcta declaraciones o documentos necesarios para practicar liquidaciones. Mismos porcentajes que para la anterior.

Tercera (art. 193 LGT): obtener indebidamente devoluciones. Idénticas cuantías.

Cuarta (art. 194 LGT): solicitud indebida de devoluciones, beneficios o incentivos fiscales. Normalmente multa del 15 por 100 de la base de la sanción, salvo que se trate de la omisión de datos relevantes o la inclusión de algunos falsos, para los que se impondrá una multa fija de 300 euros.

Quinta (art. 195 LGT): determinación o acreditación improcedente de partidas positivas o negativas o créditos tributarios aparentes. Multa del 15 por 100 si son partidas a compensar o a deducir de la base imponible o del 50 por 100 si se trata de partidas a deducir en la cuota de un gravamen.

Sexta (art. 196 LGT): imputación incorrecta de bases imponibles, rentas o resultados por entidades sometidas a un régimen de imputación de rentas. Multa pecuniaria proporcional del 40 por 100.

Séptima (art. 197 LGT): imputación incorrecta de deducciones, bonificaciones o pagos a cuenta en las entidades en régimen de imputación de rentas. Multa proporcional del 75 por 100.

Octava (art. 198 LGT): no presentación en plazo de declaraciones o autoliquidaciones sin que se produzca perjuicio económico a la Hacienda Pública por ello o por no comu-

40 El art. 186 de la LGT entiende por profesiones oficiales “las desempeñadas por registradores de la propiedad y mercantiles, notarios y todos aquellos que, ejerciendo funciones públicas, no perciban directamente haberes del Estado, comunidades autónomas, entidades locales u otras entidades de derecho público". 
nicar el domicilio fiscal o las condiciones de algunas autorizaciones. En este caso la sanción varía en función de los posibles requerimientos de la Administración o si se trata de obligaciones aduaneras; así, con carácter general se impondrá una sanción fija de 200 euros o de 400 euros si son obligaciones censales o de representación legal. Si se trata de datos aislados no comunicados, la multa será de 20 euros por dato, con un mínimo de 300 euros y un máximo de 20.000 euros. Si no ha habido requerimientos de la Administración tributaria, las multas se pueden imponer en la mitad de las cuantías indicadas y si ha habido requerimiento, la sanción será compatible con la del art. 203 de la LGT. Finalmente, para las obligaciones aduaneras, las multas oscilan entre un fijo de 200 euros y un variable del 1 por 1.000 del valor de las mercancías, con un máximo de 6.000 euros.

Novena (art. 199 LGT): presentación incorrecta de declaraciones o autoliquidaciones sin perjuicio económico para la Hacienda Pública. Se acude a cuantías idénticas a la anterior.

Décima (art. 200 LGT): incumplimiento de obligaciones contables y registrales. La norma acude aquí a cierto casuismo y se imponen desde multas fijas de 150 a 300 euros a variables del 1 por 100 de los cargos, abonos o anotaciones incorrectas, con un máximo de 6.000 euros, dependiendo de la gravedad de las actuaciones y de la incidencia de las mismas en las obligaciones fiscales.

Undécima (art. 201 LGT): incumplimiento de obligaciones de facturación o documentación. Para las infracciones graves multa del 2 por 100 del conjunto de operaciones incorrectas y para las muy graves, multa del 75 por 100.

Duodécima (art. 202 LGT): incumplimiento de obligaciones relativas a la utilización y a la solicitud del número de identificación fiscal (NIF) o de otros números o códigos. Si se califica como leve, multa fija de 150 euros; si es grave, multa proporcional del 5 por 100 y si es muy grave, multa fija de 30.000 euros.

Decimotercera (art. 203 LGT): resistencia, obstrucción, excusa o negativa a las actuaciones de la Administración tributaria. Se aplicará una multa fija o proporcional que variará desde 150 a 600.000 euros, en función del tipo de conducta y del porcentaje de las operaciones o informaciones a las que se ha imposibilitado el acceso de la Administración tributaria.

Decimocuarta (art. 204 LGT): incumplimiento del deber de sigilo exigido a los retenedores y a los obligados a realizar ingresos a cuenta. Multa de 300 euros por cada dato o conjunto de datos referidos a una misma persona o entidad.

Decimoquinta (art. 205 LGT): incumplimiento de la obligación de comunicar correctamente datos al pagador de rentas sometidas a retención o ingreso a cuenta. Si se califica como leve, multa proporcional del 35 por 100 y si es muy grave, del 150 por 100.

Decimosexta (art. 206 LGT): incumplimiento de la obligación de entregar el certifica190 do de retenciones o ingresos a cuenta. Para este último supuesto, multa fija de 150 euros. 
Como conclusión podemos indicar que la normativa ha optado en la nueva regulación desde 2003 por un casuismo que podemos juzgar, a nuestro parecer, como excesivo, al mismo tiempo que se complica innecesariamente la cuantificación con circunstancias agravantes o con medios de calificación muy similares. Desde estas páginas y, a causa de los límites de este trabajo, solo pretendemos dar noticia de todo ello y tratar de aportar cierta claridad al tema.

\section{Criterios de graduación y cuantificación}

Después de señalar las diferentes multas fijas o proporcionales, así como las sanciones no pecuniarias accesorias que están previstas para el numeroso elenco de infracciones tributarias, resta, en aras de determinar la correcta cuantificación de las sanciones, referirnos a diversos criterios de graduación de las mismas contenidos en los arts. 187 y 188 de la LGT. Para ello dividiremos el estudio en dos bloques, en función de si son favorables o no al sujeto infractor ${ }^{41}$.

Entre las no favorables se encuentran tres circunstancias, todas ellas previstas en el art. 187 de la LGT:

Primera: la comisión repetida de infracciones tributarias, que se considera producida si el sujeto infractor hubiera sido sancionado por una infracción de la misma naturaleza en virtud resolución firme en vía administrativa dentro de los cuatro años anteriores a la comisión de la infracción. El precepto prevé que se considerarán de la misma naturaleza aquellas que se incluyan en el mismo artículo, salvo las de los arts. 191, 192 y 193 de la LGT que se entenderán todas ellas similares entre sí a estos efec$\operatorname{tos}^{42}$. Si concurre este criterio de graduación se incrementará la sanción desde 5 a 25 puntos porcentuales, en función de si se trata de una infracción leve, grave o muy grave $^{43}$.

Segunda: si se ha producido perjuicio económico para la Hacienda Pública; para ello, se calculará en virtud del porcentaje existente entre la base de la sanción y la cuantía total de la deuda tributaria correspondiente. La sanción se ampliará entre 10 y 25 puntos porcentuales dependiendo de dicho perjuicio.

41 Hay que advertir que el apartado 2 del art. 187 de la LGT permite que todos los criterios de graduación mencionados y analizados en el texto se puedan aplicar de manera simultánea.

42 Vid., en este sentido, los interesantes comentarios de Ribes Ribes, A.: "Reincidencia y ejecutividad de la sanción: reflexiones críticas en torno al artículo 187.1. a) de la Ley General Tributaria”, Nueva Fiscalidad, núm. 2, 2005, pp. 64 y ss.

43 Para concretar situaciones dudosas y para tratar de aclarar la aplicación de este criterio, el art. 5 del RGRST indica que "cuando el sujeto infractor hubiese sido sancionado por varias infracciones de la misma naturaleza (...) de todas ellas se computará como único antecedente la infracción cuya calificación haya resultado más grave. 2. Cuando se realicen actuaciones relativas a una determinada obligación tributaria, no constituirá antecedente la imposición de sanciones por infracciones de la misma naturaleza derivadas de liquidaciones provisionales referidas a la misma obligación (...)". 
Tercera: si ha existido incumplimiento sustancial de la obligación de facturación o documentación. En este caso, se trata también de una infracción por sí misma tipificada y como un medio de calificar una infracción como cometida con medios fraudulentos. Si se toma como criterio de graduación, es preciso que afecte a más del 20 por 100 del importe de las operaciones sujetas al deber de facturación ${ }^{44}$. La oscilación de la multa dependerá de cada una de las infracciones y de las cuantías en ellas contenidas y que hemos expuesto anteriormente ${ }^{45}$.

Como criterio favorable al sujeto infractor solamente está previsto el acuerdo o conformidad del interesado, previsto en el art. 187-1-d) de la LGT; para ello, se necesitan dos vías de actuación:

En primer lugar, si se trata de procedimientos de verificación de datos y de comprobación limitada de la Administración tributaria, salvo que se requiera conformidad expresa, se entenderá producida la misma si la liquidación que resulte no sea objeto de recurso o de reclamación económico-administrativa ${ }^{46}$.

En segundo término, si se está inmerso en un procedimiento de inspección tributaria, se aplicará este criterio de graduación si el obligado tributario suscribe el acta correspondiente con acuerdo o la llamada acta de conformidad ${ }^{47}$.

44 En este sentido, el art. 6 del RGRST establece que "cuando un procedimiento de comprobación o investigación tenga por objeto varios tributos con períodos impositivos o de liquidación de diferente duración, la apreciación del criterio de incumplimiento sustancial de la obligación de facturación o documentación (...) se realizará tomando en consideración cada uno de los períodos de menor duración".

45 Como se observa fácilmente las posibilidades de inducir a error por las diferentes conceptuaciones que realiza la norma tributaria son muy elevadas, ya que una misma conducta -defectos de facturaciónpuede ser utilizada como medio de calificación, como criterio de graduación o como infracción autónoma. Recuérdese que, consciente el legislador de este problema, ha introducido el apartado 2 del art. 180 de la LGT en el que se impide sancionar de forma autónoma una conducta que deba entenderse como criterio de graduación o de calificación de una infracción tributaria, como ya hemos señalado en un epígrafe anterior.

A mayor abundamiento, podemos citar la opinión de Simón Acosta, E., cuando escribe: “Los criterios de graduación sólo se pueden utilizar 'en la medida en que resulten aplicables', según dice la cabecera del apartado 1 del artículo 187 de la LGT. Esta expresión admite una doble interpretación.

Puede referirse, en primer lugar, a los casos en que el criterio de graduación es compatible con la infracción cometida: por ejemplo, el criterio de perjuicio económico sólo es aplicable a las infracciones de resultado, puesto que si no hay perjuicio este criterio no puede desplegar sus efectos.

Pero también puede interpretarse que los criterios son aplicables cuando la norma reguladora de la infracción los menciona de forma expresa. A favor de esta interpretación puede alegarse que algunos de los preceptos de la LGT en que se regulan los tipos de infracción establecen expresamente los criterios de graduación que se aplicarán... El texto de la ley admite cualquiera de las dos soluciones”. (Vid.: "Capítulo IX. La potestad sancionadora", ob. cit., pp. 864 y 865).

46 Como escribe Pérez-Piaya Moreno, C.: “... se agravan las deficiencias en lo referente a la pretendida separación de procedimientos desde el momento en que la reducción en la sanción se pierde por el hecho de impugnar no precisamente dicha sanción, sino de recurrir la liquidación: se puede recurrir la sanción sin perder la reducción por conformidad del 30\% pero siempre que no se impugne la regularización practicada. La Ley, con la dicción del precepto estudiado, vuelve a demostrar que la base del procedimiento sancionador no se halla sino en el previo expediente de regularización tributaria, con lo que lo que ocurra en este último, implicará irremediablemente un determinado devenir y una concisas consecuencias en el sancionador". (Vid.: "Reducción de sanciones por la prestación de conformidad en sede de regularización”, Nueva Fiscalidad, núm. 8, 2007, pp. 42 y 43).

47 Evidentemente excede los límites de este trabajo exponer con detalle los tipos de actas que se pueden firmar en el marco de un procedimiento de inspección fiscal; así, a título de ejemplo, indicaremos 
Para las dos, el art. 188 de la LGT establece que la sanción impuesta se reducirá en un 50 por 100 para las actas con acuerdo y en un 30 por 100 en los supuestos de conformidad. A su vez, el apartado 3 del citado art. 188 permite una reducción extra, una vez aplicada la del 30 por 100 -lo que nos permite deducir que este mayor descuento no se aplica para la del 50 por 100-, del 25 por 100 si se ingresa en los plazos concedidos por la Administración tributaria o si no se interpone recurso contra la liquidación o la sanción.

\section{Procedimiento sancionador tributario}

La siguiente cuestión que debemos abordar, siquiera sea muy brevemente, es el procedimiento regulado en la LGT (arts. 207 a 212) para imponer las sanciones. Como es lógico, nos ceñiremos a explicar las novedades que imponen dichos preceptos en relación con la LGT de 1963 derogada y las especialidades frente al procedimiento administrativo común.

Lo primero que hay que señalar es que el art. 208 de la LGT advierte que el procedimiento se tramitará de forma separada al de la aplicación del tributo correspondiente que ha dado lugar a la sanción, es decir, la liquidación correcta del gravamen. Sin embargo, la norma permite que se renuncie expresamente por parte del sujeto infractor y decida continuar con un procedimiento conjunto para ambos. La opción indicada es voluntaria en todos los casos, salvo si el particular decide firmar un acta con acuerdo de la Inspección tributaria, en la que se sobreentiende y se "obliga" a que se tramite de manera conjunta, ya que es uno de los aspectos que deben consignarse expresamente en dichas actas.

Por lo demás, el procedimiento sigue los parámetros habituales de todo procedimiento administrativo, con las garantías oportunas de notificación, alegaciones y el resto de derechos, entre ellos, los contenidos en el art. 34 de la propia LGT ${ }^{48}$.

El inicio del procedimiento se produce de oficio, mediante la notificación del órgano competente y su instrucción contempla todos los medios de prueba admitidos en derecho, así como la toma de medidas cautelares previstas por la LGT para evitar el impago de las deudas tributarias correspondientes.

que los arts. 154 y ss. de la LGT prevén las actas con acuerdo, de conformidad o de disconformidad. A dichos preceptos nos remitimos para un mejor estudio del tema.

48 Estos derechos han sido una concreción en la nueva LGT de los que anteriormente se hallaban en la Ley de Derechos y Garantías de los Contribuyentes de 1998 y que, entre otros, son el de utilización de lenguas oficiales en el territorio, el de conocer el estado de tramitación del procedimiento, el de conocer la identidad de las autoridades y el personal que tramita los expedientes, el derecho a solicitar certificación y copia de las actuaciones, el de no aportar documentos ya en poder de la Administración tributaria, el derecho al carácter reservado de los datos y las actuaciones, el de ser tratado con el debido respeto y consideración, el de llevar a cabo las actuaciones de la forma menos gravosa posible y el derecho a formular quejas y sugerencias por el funcionamiento de la Administración tributaria. 
A pesar de las garantías y de las previsiones legales al respecto, hay que poner de manifiesto que el órgano competente para el procedimiento sancionador es el mismo que para liquidar el gravamen de que se trate, como advierte expresamente el art. 20 del RGRST ${ }^{49}$, lo cual suscita dudas acerca de la objetividad e imparcialidad del mismo ${ }^{50}$.

A continuación, en la propuesta de resolución se contendrá la afirmación o no de que existe responsabilidad por parte del sujeto infractor y la sanción propuesta. En este momento el órgano instructor notificará al particular dicha propuesta para que alegue lo que desee en el plazo de 15 días.

Seguidamente se pasará a la fase de resolución, con la imposición o no de la sanción que corresponda ${ }^{51}$, destacando en este momento la prohibición, contenida en el apartado 2 del art. 211 de la LGT, de que el procedimiento sancionador en materia tributaria no puede exceder de un tiempo máximo de seis meses desde la notificación del inicio del mismo. En caso de pasar dicho lapso de tiempo, se entenderá que ha caducado el procedimiento, archivándose las actuaciones e impidiendo que se inicien nuevas con el mismo objeto.

Finalmente hay que indicar que los recursos frente a las sanciones se pueden interponer de manera independiente al de la liquidación de los tributos, como no podía ser de otra manera, al tener tramitación separada. En todo caso, el art. 212 de la LGT prevé la impugnación conjunta de ambos (sanción y liquidación) a opción del sujeto pasivo ${ }^{52}$.

49 El precepto tiene el siguiente tenor literal: "Salvo que una disposición establezca expresamente otra cosa, la atribución de competencias en el procedimiento sancionador será la misma que la del procedimiento de aplicación de los tributos del que derive".

50 Según el parecer de Aníbarro Pérez, S. y Sesma Sánchez, B., que compartimos: “... se consagra como regla la identidad orgánica entre el órgano competente para liquidar y el órgano competente para proponer la sanción o sancionar o entre el órgano que haya instruido un procedimiento de gestión y quien asuma la instrucción del procedimiento sancionador subsiguiente... A nuestro juicio, la objetividad e imparcialidad que deben presidir la valoración de la culpabilidad del sujeto infractor en un procedimiento sancionador no se garantiza si el mismo órgano que ha descubierto los indicios de infracción tributaria y que, en consecuencia, ha propuesto una liquidación, que se ha formado una opinión, inevitablemente subjetiva, acerca de la conducta y culpabilidad del sujeto infractor, va a ser el mismo que instruya el expediente sancionador y que proponga la sanción o la imponga directamente”. (Vid.: “Capítulo VII. Infracciones y sanciones tributarias y procedimiento”, en la Obra Colectiva: Los nuevos reglamentos tributarios, Thomson-Civitas, Navarra, 2006, pp. 316 y 317).

51 El apartado 5 del art. 211 de la LGT enumera los órganos competentes para la imposición de sanciones del modo siguiente: “a) El Consejo de Ministros, si consisten en la suspensión del ejercicio de profesiones oficiales, empleo o cargo público.

b) El Ministro de Hacienda, el órgano equivalente de las comunidades autónomas, el órgano competente de las entidades locales u órganos en quienes deleguen, cuando consistan en la pérdida del derecho a aplicar beneficios o incentivos fiscales cuya concesión le corresponda o que sean de directa aplicación por los obligados tributarios, o de la posibilidad de obtener subvenciones o ayudas públicas o en la prohibición para contratar con la Administración pública correspondiente.

c) El órgano competente para el reconocimiento del beneficio o incentivo fiscal, cuando consistan en la pérdida del derecho a aplicar el mismo, salvo lo dispuesto en el párrafo anterior.

d) El órgano competente para liquidar o el órgano superior inmediato de la unidad administrativa que ha propuesto el inicio del procedimiento sancionador".

52 Para un mayor detalle del procedimiento sancionador nos remitimos a los preceptos que hemos citado en el texto de la LGT y a los arts. 20 a 28 del RGRST, tantas veces citado. También se pueden 


\section{Ejecución de las sanciones tributarias}

Para finalizar el apartado general sobre las sanciones previstas para las infracciones tributarias resta examinar que la ejecución de las mismas se llevará a cabo por parte de la Administración tributaria de acuerdo a la normativa general en la materia; en efecto, el art. 190-3 de la LGT prescribe que "la recaudación de las sanciones se regulará por las normas incluidas en el capítulo V del título III de esta ley”. Dicho capítulo contempla el procedimiento de recaudación, tanto en período voluntario como en período ejecutivo, así como el procedimiento de apremio y embargo, cuyo detalle excede los límites de este trabajo.

Únicamente queda comentar la posible suspensión de la ejecución de las sanciones, como admite el art. 29 del RGRST en caso de que se haya interpuesto en tiempo y forma un recurso o reclamación económico-administrativa ${ }^{53}$. En este caso, se aplicará de forma automática por los órganos competentes sin necesidad de solicitud del interesado y para el correcto funcionamiento del sistema, dicho precepto obliga a los órganos que tramiten recursos o reclamaciones a comunicar a los ejecutores de sanciones, en el plazo de diez días, las decisiones o incidencias que se produzcan ${ }^{54}$.

\section{EXTINCIÓN DE LA RESPONSABILIDAD POR INFRACCIONES Y SANCIONES TRIBUTARIAS}

\section{Extinción de la responsabilidad por infracciones. Causas eximentes de la responsabilidad (reenvío)}

La última parte del apretado estudio que estamos llevando a cabo sobre la potestad sancionadora de la Administración tributaria la dedicamos a las formas en que se extingue la responsabilidad por las infracciones y sanciones fiscales. En este epígrafe nos ocupamos de los medios para la extinción de las infracciones, mientras que en el siguiente analizamos los correspondientes para las sanciones.

Con carácter previo hay que señalar que se deben entender reproducidas aquí las causas eximentes de la responsabilidad que ya hemos abordado al tratar el principio de culpabilidad en este ámbito, por lo que a lo allí indicado nos remitimos.

\footnotetext{
consultar: Orena Domínguez, A.: “Notas sobre el procedimiento sancionador”, Nueva Fiscalidad, núm. 11, 2005, pp. 33 y ss y el libro de Hermosín, M.: Procedimiento Sancionador Tributario. Cuestiones Problemáticas, ob. cit., pp. 125 y ss., por lo que respecta a la nueva LGT y a las consideraciones que efectúa la autora en páginas anteriores sobre la evolución histórica del mismo.

53 Que, como comprobamos, no puede haberse realizado si se quiere tener derecho a una de las reducciones por conformidad del sujeto infractor con la sanción propuesta.

54 El apartado 2 del citado art. 29 del RGRST a su vez prevé que "una vez la sanción sea firme en vía administrativa, los órganos de recaudación no iniciarán las actuaciones del procedimiento de apremio mientras no concluya el plazo para interponer el recurso contencioso-administrativo. Si durante ese plazo el interesado comunica a dichos órganos la interposición del recurso con petición de suspensión, ésta se mantendrá hasta que el órgano judicial adopte la decisión que corresponda en relación con la suspensión solicitada".
} 
En cuanto a las causas de extinción propiamente dichas, el art. 189 de la LGT admite dos: el fallecimiento del sujeto infractor y la prescripción del derecho de la Administración para imponer las sanciones.

Por lo que respecta al fallecimiento, a diferencia de la sucesión de deudas tributarias, que sí son extensibles a los herederos o legatarios del causante (art. 39 de la LGT), las infracciones no, de manera que dicho óbito provoca la extinción de las mismas $^{55}$. En cambio, como ya hemos indicado en el epígrafe sobre los sujetos infractores, para las personas jurídicas y entidades sin personalidad, sí que se transmiten a los liquidadores, socios o partícipes y comuneros correspondientes ${ }^{56}$.

En lo que se refiere a la prescripción, sigue un régimen jurídico casi idéntico a los supuestos previstos para liquidar una deuda tributaria; en efecto, el plazo es de 4 años y se empieza a contar desde que se cometió la infracción; se interrumpirá conforme a las actuaciones de la Administración tributaria o del sujeto infractor relativas a la imposición de las mismas o al planteamiento de cualquier tipo de recurso y, finalmente, esta causa de extinción se aplicará de oficio por la Administración tributaria y puede ser motivo de oposición a la recaudación de las sanciones.

\section{Extinción de la responsabilidad por sanciones}

Esta materia se encuentra regulada en el art. 190 de la LGT en el que se establece como causas de la extinción el pago o cumplimiento, la prescripción del derecho a exigir dicho pago, la compensación, la condonación y el fallecimiento de todos los obligados a satisfacerlas.

El pago, como es lógico, es el modo habitual de finalizar la responsabilidad del sujeto infractor y para ello, la norma se remite, como ya hemos examinado, al Capítulo $\vee$ del Título III de la propia LGT en cuanto a la recaudación.

Respecto a la prescripción, compensación y condonación, el art. 190 citado reenvía al Capítulo IV del Título II de la LGT, referido a las mismas causas de extinción pero, en este caso, de las deudas tributarias; por lo tanto, deben considerarse aquí repro-

55 El art. 39 de la LGT tiene el siguiente tenor literal: " $A$ la muerte de los obligados tributarios, las obligaciones tributarias pendientes se transmitirán a los herederos, sin perjuicio de lo que establece la legislación civil en cuanto a la adquisición de la herencia.

Las referidas obligaciones tributarias se transmitirán a los legatarios en las mismas condiciones que las establecidas para los herederos cuando la herencia se distribuya a través de legados y en los supuestos en que se instituyan legados de parte alícuota.

En ningún caso se transmitirán las sanciones".

56 El apartado 5 del art. 40 de la LGT prevé expresamente que "las sanciones que pudieran proceder por las infracciones cometidas por las sociedades y entidades a las que se refiere este artículo serán exigibles a los sucesores de las mismas, en los términos establecidos en los apartados anteriores, hasta el límite del valor de la cuota de liquidación que les corresponda". 
ducidas las consideraciones generales que realiza la LGT para la dichas instituciones jurídicas. La única salvedad consiste en señalar que la condonación de las sanciones ahora solo puede operarse mediante ley (de acuerdo con el art. 75 de la LGT, al que se remite el art. 190 del mismo cuerpo legal), lo que cambia el criterio frente a la LGT de 1963 que permitía el perdón de las sanciones por parte de un órgano administrativo a través de una norma reglamentaria. Esto supone un avance importante respecto a dicha regulación precedente ${ }^{57}$.

Por último, el fallecimiento ya hemos visto que extingue la infracción para las personas físicas, por lo que sucede lo mismo para las sanciones; en cuanto a las personas jurídicas y entidades sin personalidad, debe interpretarse la afirmación de la norma de que se extinguen las sanciones si fallecen todas las personas obligadas a satisfacerlas, en el sentido de desaparición de las personas físicas que han heredado las sanciones de una persona jurídica, es decir, sus socios, liquidadores, partícipes o comuneros.

57 Como escriben Almenar Belenguer, J. y Ripley Soria, D.: “Dentro de las causas de extinción previstas en ese Capítulo, debe hacerse mención especial a la condonación, que deja de estar regulada con carácter específico para las sanciones, como hacía el viejo art. 89.2 de la LGT/1963, rigiéndose por la norma general del art. 75 de la ley. Por tanto, ya no cabe la condonación graciable de las sanciones, como institución específica frente a la condonación del resto de elementos tradicionales de la deuda tributaria, que operará siempre mediante una ley”. (Vid.: “Título IV. La potestad sancionadora”, en la Obra Colectiva: Comentarios a la Nueva Ley General Tributaria, Thomson-Aranzadi, Navarra, 2004, p. 1316). 
